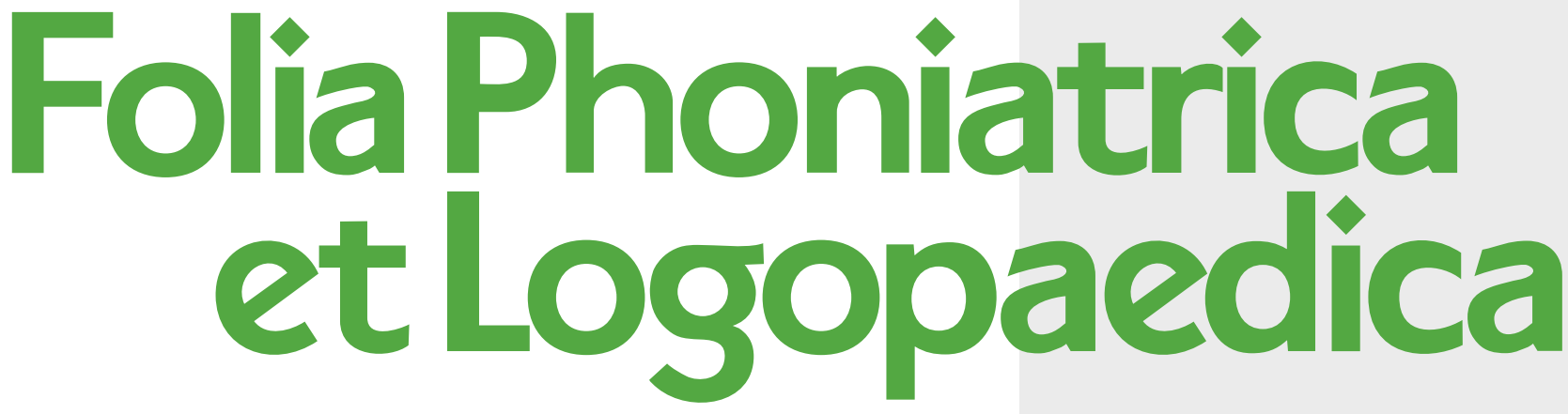

International Journal of

Phoniatrics, Speech Therapy and

Communication Pathology

\title{
Speech Motor Control: Current Perspectives on Development and Disorders
}

Guest Editors

Anja Staiger, Munich

Theresa Schölderle, Munich 


\section{The interdisciplinary "hub" for researchers, clinicians and public health professionals}

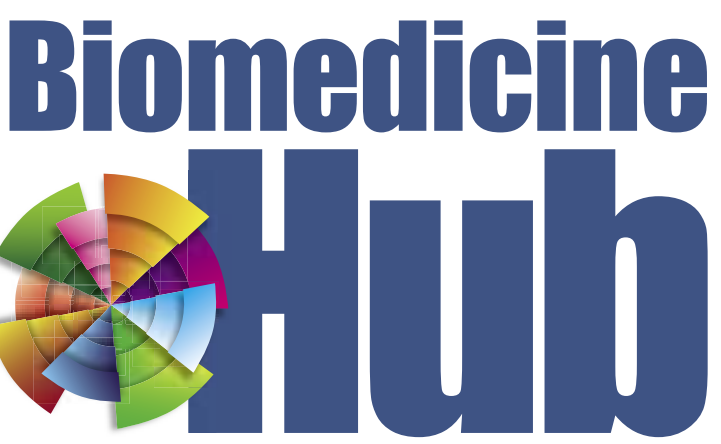

\section{www.biomedicinehub.com}

\section{An international Editorial Board with more than 170 renowned specialists guarantees high-quality and relevant content.}

There is currently no Article Processing Charge (APC).
- open access

- peer-reviewed

- fast online publication

Biomedicine Hub is an interdisciplinary journal: a 'hub' for researchers, clinicians and public health professionals across biomedical disciplines to share research findings, ideas, theories, experimental results and clinical experience.

Biomedicine Hub aims at facilitating the exchange of knowledge between disciplines, with a focus on translational science for the development of cutting-edge technologies and the improvement of health care. A further focus is on emerging interdisciplinary fields at the forefront of medicine. 
Official Organ of the International Association of Logopedics and Phoniatrics (IALP)

\section{FoliaPhoniatrica et Logopaedica}

International Journal of

Phoniatrics, Speech Therapy and Communication Pathology

Founded in 1947 by R. Luchsinger, M. Seeman and J. Tarneaud

Edited by R. Luchsinger 1947-1966; R. Luchsinger and E. Loebell 1967-1975;

E. Loebell 1976-1995; S. Fex 1995-2001; H.K. Schutte 2001-2010; G. Weismer 2011-2016

\section{Editor-in-Chief}

M. Robb, University Park, P.A.

IALP

President:

Lilly Cheng, San Diego, Calif.

Icheng@mail.sdsu.edu

Secretary:

Tamer Abou-Elsaad, Mansoura

taboelsaad@hotmail.com

Treasurer:

Brian Shulman, New York, N.Y.

brian.shulman@shu.edu

IALPOffice

c/o Vanessa Borg, Birkirkara

office@ialp.info

www.ialp.info

\section{Associate Editors}

Aphasia:

Philippe F. Paquier, Brussels

Audiology:

Gregory O'Beirne, Christchurch, NZ

Child Language:

Nina Capone Singleton, South Orange,

NJ

Child Speech:

Annette Fox-Boyer, University of Lübeck,

Germany

Dyshpagia:

Margret Walshe, Dublin

Fluency:

Michael Blomgren, Salt Lake City

Motor Speech Disorders:

Hayo Terband, Utrecht

Voice:

Manwa Lawrence Ng, Hong Kong 


\section{Folia Phoniatrica et Logopaedica}

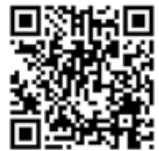

\section{Guidelines for Authors}

We strongly encourage authors to read

the Guidelines for Authors at

www.karger.com/fpl_guidelines prior to

submitting an article.

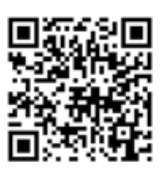

\section{Journal Contact}

For questions or comments, please contact the persons responsible who can be found at http://www.karger.com/Journal/Contact/224177.

ISSN Print Edition: 1021-7762

ISSN Online Edition: 1421-9972

Journal Homepage: www.karger.com/fpl Bibliographic Indices: This journal is regularly listed in bibliographic services, including Current Contents ${ }^{\circledR}$ and PubMed/MEDLINE.

Publication Data: Folia Phoniatrica et Logopaedica is published 6 times a year. Volume 71 with 6 issues appears in 2019.

Copyright: $\odot 2019$ S. Karger AG, Basel (Switzerland). All rights reserved. No part of this publication may be translated into other languages, reproduced or utilized in any form or by any means, electronic or mechanical, including photocopying, recording, microcopying, or by any information storage and retrieval system, without permission in writing from the publisher.

Disclaimer: The statements, opinions and data contained in this publication are solely those of the individual authors and contributors and not of the publisher and the editor(s). The appearance of advertisements in the journal is not a warranty, endorsement, or approval of the products or services advertised or of their effectiveness, quality or safety. The publisher and the editor(s) disclaim responsibility for any injury to persons or property resulting from any ideas, methods, instructions or products referred to in the content or advertisements.

\section{Journal Information}

\section{Aims and Scope}

Published since 1947, Folia Phoniatrica et Logopaedica provides a forum for international research on the anatomy, physiology, and pathology of structures of the speech, language, and hearing mechanisms. Original papers published in this journal report new findings on basic function, assessment, management, and test development in communication sciences and disorders, as well as experiments designed to test specific theories of speech, language, and hearing function. Review papers of high quality are also welcomed.

\section{Subscription Orders:}

Orders can be placed at agencies, bookstores, or directly with the Publisher.

\section{S. Karger AG}

Medical and Scientific Publishers

Allschwilerstrasse 10

$\mathrm{CH}-4009$ Basel

Switzerland

\section{t: +41613061111 \\ f: +41613061234 \\ e: karger@karger.com \\ w: www.karger.com}

(for courier services only:

Allschwilerstrasse 10

CH-4055 Basel)

\section{Change of Address:}

Both old and new addresses should be sent to the subscription source.
Subscription Rates: Subscriptions run for a full calendar year. Prices are given per year.

\section{Personal subscription:}

$\begin{array}{ll}\text { Print or Online } & \text { Print+Online combined } \\ \text { CHF } 450.00 & \text { CHF } 503.00 \\ \text { EUR } 405.00 & \text { EUR } 448.00 \\ \text { USD } 489.00 & \text { USD } 542.00\end{array}$

\section{postage and handling}

(added to print and print+online)

CHF 50.40 Europe, CHF 72.00 Overseas

EUR 45.60

USD 69.60

\section{Institutional subscription:}

$\begin{array}{ll}\text { Print or Online } & \text { Print+Online } \\ \text { CHF } 1499.00 & \text { CHF } 1724.00 \\ \text { EUR 1350.00 } & \text { EUR } 1553.00 \\ \text { USD } 1629.00 & \text { USD } 1873.00\end{array}$

\section{postage and handling}

(added to print and print+online)

CHF 63.00 Europe, CHF 90.00 Overseas

EUR 57.00

USD 87.00

Back Volumes and Single Issues: Information on availability and prices of single print issues and print or electronic back volumes can be obtained from Customer Service at service@karger.com. 


\section{Contents}

See the journal website for contents

KARGER $\begin{aligned} & \text { Basel } \cdot \text { Freiburg } \cdot \text { Paris } \cdot \text { London } \cdot \text { New York } \cdot \text { New Delhi } \cdot \text { Bangkok } \cdot \\ & \text { Beijing } \cdot \text { Tokyo } \cdot \text { Kuala Lumpur } \cdot \text { Singapore } \cdot \text { Sydney }\end{aligned}$ 
Editor

C.T. Best, Bankstown, NSW (Australia)

Associate Editors

D. Derrick,

Christchurch (New Zealand)

S. Frota, Lisbon (Portugal)

W. Gu, Nanjing (China)

A. Jongman, Lawrence, KS (USA)

G. Khattab, Newcastle upon Tyne (United Kingdom)

A. Kochetov, Toronto, ON (Canada)

L. Polka, Montreal, QC (Canada)

R. Smith, Glasgow

(United Kingdom)

P.C.M. Wong, Hong Kong

(China)
Book Reviews

O. Niebuhr, Sonderborg (Denmark)

Editorial Board

P.A. Barbosa, Campinas (Brazil)

W.J. Barry,

Sindlesham-Wokingham

(United Kingdom)

A. Beckford Wassink, Seattle, WA (USA)

P.S. Beddor, Ann Arbor, MI (USA)

A. Bradlow, Evanston, IL (USA)

K. Dziubalska-Kołaczyk,

Poznań (Poland)

J. Fletcher, Parkville, VIC

(Australia)

L. Goldstein,

Santa Monica, CA (USA)

J. Hajek, Melbourne, VIC

(Australia)
S. Hawkins, Cambridge (United Kingdom)

R. Hayes-Harb,

Salt Lake City, UT (USA)

D. House, Stockholm (Sweden)

S. Kawahara, Tokyo (Japan)

L. Ménard, Montreal, QC

(Canada)

C. Mooshammer, Berlin

(Germany)

F. Nolan, Cambridge

(United Kingdom)

R. Ogden, York

(United Kingdom)

M. Pouplier, Munich (Germany)

D. Recasens, Barcelona (Spain)

R. Walker,

Los Angeles, CA (USA)

K. Watson, Christchurch

(New Zealand)

D.H. Whalen, New York, NY

(USA)
Phonetica
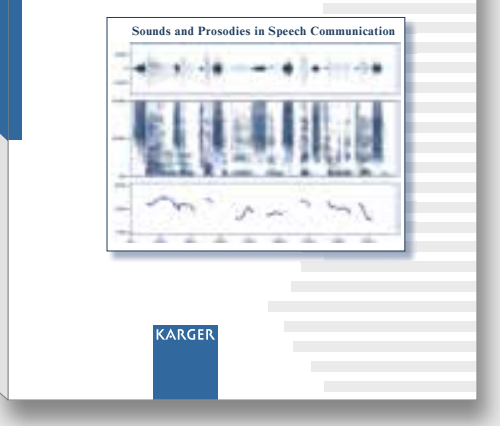

Contemporary interdisciplinary research on phonetics employs a wide range of approaches, from instrumental measures to perceptual and neurocognitive procedures, to computational modelling, for investigating the properties and principles of phonetics in communicative settings across the world's languages. It also ranges across styles, types of language users, and communicative modalities (speech, sign, song). Phonetica is an international forum for phonetic science that covers all aspects of the subject matter, from phonetic and phonological descriptions, to articulatory and signal analytic measures of production, to perception, acquisition, and phonetic variation and change. Phonetica thus provides a platform for a comprehensive understanding of producer-perceiver interaction across languages and dialects, and of learning throughout the lifespan and across contexts. Papers published in this journal report expert original work that deals both with theoretical issues, new empirical data, and innovative methods and applications that help to advance the field.

Phonetica has introduced a new format, the Book Discussion, which reconsiders classic monographs in light of current issues in phonetic science. Book Discussion proposals/submissions are welcome.
Selected contributions

- Explaining Coronal Reduction: Prosodic Structure and Articulatory

Posture: Parrell, B. (Newark, DE); Narayanan, S. (Los Angeles, CA)

- The Effect of Focus and Phrase Position on East Norwegian Lexical

Tonal Accents: Kelly N.E. (Beirut); Smiljanic R. (Austin, TX)

- Rhythm, Timing and the Timing of Rhythm: Arvaniti, A. (San Diego, CA)

- Individual Talker and Token Covariation in the Production of Multiple

Cues to Stop Voicing: Clayards M. (Montreal, QC)

- Nonnative Accent Discrimination with Words and Sentences: Atagi E.;

Bent T. (Bloomington, IN)

- Dialect Interference in Lexical Processing: Effects of Familiarity and Social

Stereotypes: Clopper, $\mathbf{C}$. (Columbus, $\mathrm{OH}$ )

- Stress Effects in Vowel Perception as a Function of Language-Specific

Vocabulary Patterns: Warner, N. (Tuscon, AZ); Cutler, A. (Penrith South, NSW) - BOOK DISCUSSION: R.H. Stetson, Motor Phonetics: A Study of Speech

Movements in Action: Barbosa, A. (Campinas)

\section{Phonetica}

Founded: 1957

Category: Basic Research

Fields of Interest: Phonetics, Communication Disorders

Listed in bibliographic services, including:

PubMed/MEDLINE, Web of Science, Google Scholar, Scopus

2019: Volume 76

6 issues per volume

Language: English

ISSN 0031-8388

e-ISSN 1423-0321 


\section{Folia Phoniatrica et Logopaedica}

\section{Speech Motor Control: Current Perspectives on Development and Disorders}

This special topic issue of Folia Phoniatrica et Logopaedica is dedicated to speech motor control and its disorders. One of the major objectives of research is to develop the theoretical basis for these most diverse conditions and to translate this knowledge into valid diagnostic and therapeutic approaches for a specific and patient-oriented clinical management. The included studies of this issue cover a wide spectrum of neurological conditions and associated speech disorders. The articles address the impact of speech motor disorders on life course and social acceptedness, and deal with recent clinical developments, as well as with the scrutiny of well-established assessment methods. The first four papers comprise studies on motor speech in childhood and adolescence. Another six papers focus on disorders in adults. Therefore the articles cover peaks of speech motor disorders in different stages of life.

This special topic issue is of interest to all professional groups in the field of speech and language therapy and research - in particular to those specialized on dysarthria and apraxia of speech in children and adults. Readers will expand their knowledge on speech motor control and its disorders. They will receive new impetus for research and clinical practice. 